\title{
The reciprocal interaction between sleep and type 2 diabetes mellitus: facts and perspectives
}

\author{
R.C. Martins, M.L. Andersen and S. Tufik \\ Departamento de Psicobiologia, Escola Paulista de Medicina, Universidade Federal de São Paulo, \\ São Paulo, SP, Brasil
}

Correspondence to: M.L. Andersen, Departamento de Psicobiologia, EPM, UNIFESP, Rua Napoleão de Barros, 925, 04021-002 São Paulo, SP, Brasil

Fax:+55-11-5572-5092. E-mail: mandersen@psicobio.epm.br

Type 2 diabetes mellitus is a systemic disease characterized by intolerance to glucose and peripheral resistance to insulin. This endocrine disease affects fundamental mechanisms of the central nervous system and jeopardizes the balance of vital functions such as the cardiovascular and circadian rhythm. The increased prevalence of metabolic disorders in our society is aggravated by endemic voluntary postponement of bedtime and by the current sedentary lifestyle, leading to epidemic proportions of obese people. Diabetes and chronic loss of sleep share the fact that both affect millions and one is detrimental to the other. Indeed, sleep deficits have marked modulatory effects on glucose metabolism and insulin sensitivity and foster metabolic syndrome that culminates in sleep disorders like restless syndrome and sleep apnea, which in turn lead to poor sleep quality. We examine the hypothesis that these two worldwide emerging disorders are due to two interlinked cycles. In our paradigm, we establish an intimate relationship between diabetes and sleep disturbances and postulate possible mechanisms that provide support for this conjecture. In addition, we propose some perspectives about the development of the reciprocal interaction between predictor components of metabolic syndrome and sleep disturbances that lead to poor sleep quality. The ability to predict the development and identify or associate a given mode of sleep disturbance to diabetes would be a valuable asset in the assessment of both. Furthermore, major advances in care coupled with healthy lifestyles can ensure a higher quality of life for people with diabetes.

Key words: Diabetes; Metabolic syndrome; Obesity; Apnea; Sleep

Research supported by Associação Fundo de Incentivo à Psicofarmacologia (AFIP), FAPESP (No. 06/58276-8 to R.C. Martins) and CEPID (No. 98/14303-3 to S. Tufik).

Received March 23, 2007. Accepted October 15, 2007

\section{Introduction}

In the past 50 years there has been a substantial increase in lifespan for most populations. This may be attributed chiefly to epidemiological control of infectious diseases and advances in modern medicine. Consequently, a number of non-infectious chronic pathologies that were previously almost non-existent are now ubiquitous, with a major impact in economic and social terms. In both developed and developing countries there is an epidemiologic trend in which metabolic disorders have been recognized as a serious issue. Of the various metabolic diseases, type 2 diabetes mellitus was fairly rare at the beginning of the 20th century but has become a major hurdle for health care worldwide, and is likely to remain so. The estimated prevalence of diabetes was $2.8 \%$ of the population in 2000 , directly affecting 177 million individuals worldwide, a figure almost 5-fold the estimates of 10 years ago. By 2030, an estimated $4.4 \%$ of the world's population will be afflicted, corresponding to 370 million diabetics (1). Indeed, while the human and economic costs of diabetes are difficult to calculate, the total medical costs incurred annually in the US alone are close to US\$100 billion.

The majority of type 2 diabetes cases are preventable. Although there is evidence that a genetic predisposition is important in the development of this disease, the rapid 
increase in prevalence in the world shows that environmental factors, such as overweight and a sedentary lifestyle, are of major importance (2). Type 2 diabetes in particular may go unnoticed for years, since the early symptoms are typically mild and sporadic. However, this endocrine disease has been prominent for its deleterious effects in undermining various organic systems and its widespread occurrence. Diabetes promotes devastating micro- and macrovascular complications that impose an enormous strain on health care systems worldwide. The literature has documented the impact of diabetes on various organs of the body, which leads to several central nervous system alterations involving neurobehavioral and neurotransmitter problems, autonomic dysfunction, adversely affected endocrine function (3), and sleep disturbances $(4,5)$.

Associated with the endemic condition of diabetes in our society, chronic sleep loss is increasingly common in industrialized societies and affects about $45 \%$ of all adults (6). Furthermore, alterations in only one of these systems can gradually lead to marked deregulation of the other. In this respect, intriguingly, a dramatic increase in the incidence of obesity and diabetes seems to develop at the same time as self-reported sleep duration decreases, and this may indicate a close relationship between the two $(7,8)$.

Sleep is a complex behavioral state that occupies onethird of the human life span. Although viewed as a passive condition, sleep is a highly active and dynamic process. Until recently, it was believed that sleep was important primarily for restoring brain functions. However, there is increasing evidence that sleep also modulates the metabolic, endocrine and cardiovascular systems (9).

Indeed, a recent study observed a consistent difference between diabetic subjects and non-diabetic subjects in the number of disturbances per hour of sleep, indicating a possible influence of diabetes on the sleep pattern (10). The clinical and public health significance of linking sleeprelated abnormalities to abnormal glucose metabolism is of paramount significance and thus an accurate and succinct summary of the available evidence is invaluable.

Thus, the aim of this review was to select the most relevant and representative articles that have associated sleep disturbances with diabetes and to propose some perspectives about the development of the reciprocal interaction of these two emerging worldwide disorders.

\section{Metabolic syndrome}

There is increasing evidence that metabolic syndrome is an important risk factor for the onset of type 2 diabetes (11). In this respect, the odds for individuals with metabolic syndrome to develop diabetes are 5-fold higher than for normal people. Two are the features that appear to stand out as potential causative factors: resistance to insulin and abnormal fat distribution (central obesity). Yet other factors have also been implicated in the development of this syndrome including impaired tolerance to glucose, hypertension and disorders of lipid metabolism. Metabolic syndrome genesis occurs after prolonged exposure to a series of insidious factors that may originate either from a complex chain of genetic factors or from an unhealthy lifestyle, essentially affecting older individuals (12).

Metabolic syndrome is very common, affecting about $44 \%$ of the United States population over the age of 50 years (13). Among older individuals ( $\geq 50$ years old) in the United States, $17 \%$ have diabetes and $86 \%$ of these patients suffer from metabolic syndrome (13). The progress in understanding the metabolic staging of diabetes over the past few years has led to significant advances in the regimen of treatment of this devastating disease. Improvements in the treatment or prevention of the disease will depend on understanding the underlying molecular pathophysiology in more detail.

The high prevalence of metabolic syndrome has important health implications. Visceral fat accumulation observed in the obese leads to dysfunction of adipocytes. Adipose cells are responsible for the synthesis of innumerable proteins that act systemically, dubbed adipocytokines. Except for adiponectin, which prevents cardiovascular diseases as well as metabolic diseases, including type 2 diabetes, adipocytokines are responsible for the chronic inflammatory process that precedes insulin resistance and plays a fundamental role in the physiopathological mechanisms that lead to obesity in type 2 diabetes.

Leptin is the main peptide produced by adipocytes and its serum concentration represents an important peripheral signal in the regulation of food intake and energy expenditure. Leptin suppresses food intake and increases energy expenditure, with its serum levels decreasing in the fasting state and increasing after eating (14). Unlike adiponectin, the association of serum leptin concentrations with serum lipids has been inconsistent (15). Its concentration is increased in obese subjects in parallel with fat accumulation (16). Leptin is associated more with subcutaneous than visceral adipose tissue (17). Moreover, leptin concentrations have been closely correlated with alterations in lipoproteins (VLDL and HDL) typically found in insulinresistance states (18).

\section{Implications of metabolic impairments in sleep}

A consistent difference between diabetic and non- 
diabetic subjects in the incidence of sleep disturbances (especially respiratory disturbances) per hour of sleep has been reported (10) (Table 1). Insulin-dependent diabetes mellitus can lead to an overall depression of ventilatory control mechanisms (19). Indeed, several studies have shown a strong association of obstructive sleep apnea syndrome (OSAS) with obesity, male gender (androidcentral obesity), post-menopausal women, hypertension and diabetes, factors associated with metabolic syndrome (20-25). Based on the fact that excessive daytime sleepiness and fatigue are critical symptoms of sleep apnea and frequent complaints of obese people, an important study concluded that this sleep disturbance is a morbid characteristic of obese patients which might be related to metabolic/circadian abnormality of the disorder (26). Studies have clearly shown that type 2 diabetic patients sleep less than the population in general $(4,5)$. Moreover, restless syndrome is frequently found in diabetic patients leading to poor sleep quality (27). In this respect, a gradual decrease in self-reported sleep duration seems to have developed over the same period as the dramatic increase in the incidence of obesity and diabetes, indicating a close relationship between sleep cycle and diabetes $(7,8)$ (Table 1$)$.

Finally, a recent study demonstrated that $7 \mathrm{~h}$ of exercise a week significantly reduced the number of apnea events per night of sleep, regardless of body mass index, age or gender (28). Given the effects of physical exercise on insulin resistance and visceral adiposity, verified by weight control, it is possible to speculate that the favorable effect of exercise on sleep apnea occurs through the correction of metabolic abnormalities.

\section{Obesity}

The International Diabetes Federation considers obesity to be one of the main drivers of the high prevalence of metabolic syndrome, contributing to hyperglycemia and insulin resistance. This is where a striking association between obesity with type 2 diabetes mellitus can be demonstrated (29).

Obesity should be addressed as both a disease and a lifestyle issue. A majority of individuals suffering from type 2 diabetes are obese, with central visceral adiposity, and an imbalance in energy intake and expenditure that leads to numerous metabolic abnormalities (30). Insulin resistance might be the result of obesity, but might also contribute to its development. Recent insights into the biology of the adipocyte as an endocrine organ have supported this latter idea.

Feeding behavior depends on the integration of meta-

Table 1. Implications of metabolic impairments in sleep and their prevalence in specific population groups.

\begin{tabular}{|c|c|c|c|c|c|}
\hline Metabolic disorders & Sleep disturbances & Sample & Age (years) & Gender & References \\
\hline Diabetes & $\begin{array}{l}33.7 \% \text { OSAS (diabetics) } \\
8.2 \% \text { OSAS (controls) }\end{array}$ & $\begin{array}{l}184 \text { diabetics } \\
99 \text { controls }\end{array}$ & $32-57$ & $\mathrm{M} / \mathrm{F}$ & 47 \\
\hline Obesity & $\begin{array}{l}40 \% \text { men with OSAS } \\
3 \% \text { women with OSAS } \\
\text { Control }\end{array}$ & $\begin{array}{l}200 \text { obese women } \\
50 \text { obese men } \\
128 \text { controls }(80 \mathrm{~F} / 48 \mathrm{M})\end{array}$ & $16-72$ & $\mathrm{M} / \mathrm{F}$ & 32 \\
\hline $\begin{array}{l}\text { Polycystic ovary } \\
\text { syndrome }\end{array}$ & $\begin{array}{l}30 \text { times more likely to suffer } \\
\text { from sleep-disordered breathing }\end{array}$ & 53 premenopausal women & $16-45$ & $\mathrm{~F}$ & 26 \\
\hline $\begin{array}{l}54 \% \text { obese } \\
46 \% \text { overweight } \\
40 \% \text { glucose intolerance } \\
13.3 \% \text { diabetes }\end{array}$ & $40-60 \%$ OSAS & 150 healthy mildly obese & $58-67$ & M & 37 \\
\hline $\begin{array}{l}\text { High body mass index, } \\
\text { central obesity, large neck } \\
\text { circumference }\end{array}$ & $\begin{array}{l}\text { Increased stages } 1 \text { and } 2 \text { of } \\
\text { sleep } \\
\text { Decreased REM, stages } 3 \text { and } \\
4 \text { of sleep } \\
\text { Twice increased apnea }\end{array}$ & 468 diabetics & $61-74$ & $\mathrm{M} / \mathrm{F}$ & 10 \\
\hline Diabetes & $16 \%$ sleep loss & 50 diabetics & $45-65$ & $M$ & 53 \\
\hline
\end{tabular}

OSAS = obstructive sleep apnea syndrome; REM = rapid eye movements; $\mathrm{M}=$ male; $\mathrm{F}=$ female . 
bolic, autonomic, endocrine, and environmental factors coordinated with an appropriate state of cortical arousal (wakefulness). Thus, this behavior is critically dependent on appropriate sleep-wakefulness cycling. Indeed, comorbid disturbances of sleep, appetite, and metabolism are well-described symptoms of obesity (31).

Obesity is the strongest and probably most relevant risk factor for sleep disordered breathing (especially OSAS). The mechanisms underlying the effects of obesity on the risk of OSAS may be related to fat deposition in airway anatomy or alterations in upper airway function.

Significant sleep apnea is present in $40 \%$ of obese individuals, and $70 \%$ of OSAS patients are obese (32). Not only increased body weight but also fat distribution plays a major role in the development of OSAS. Of all the anthropometric variables, studies suggest that central obesity rather than more generalized distribution of body fat is an important risk factor for OSAS in obese subjects $(4,33)$. A significantly greater amount of visceral fat, resulting from the action of insulin, may be observed in sleep apneic subjects compared with obese controls (33).

\section{Insulin resistance}

The hypothesis that visceral obesity, insulin resistance and environmental factors are the principal culprits that progressively lead to worsening of metabolic syndrome and sleep disturbances has recently gained much acceptance (34). Progressive deterioration of the sleep cycle may then accelerate the worsening of visceral obesity and of metabolic syndrome by providing a stress stimulus and causing nocturnal elevations of hormones, such as cortisol

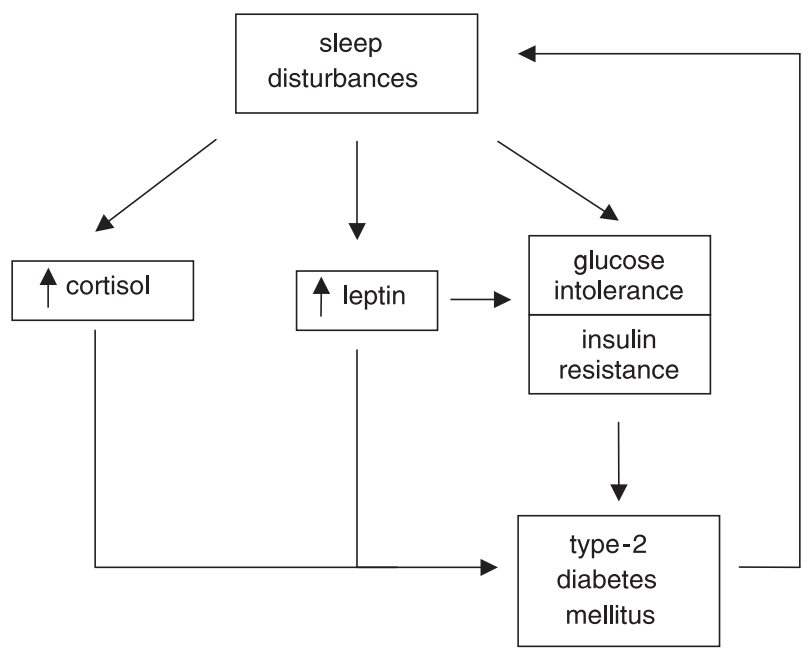

Figure 1. Potential interrelationships between sleep disturbances, glucose metabolism, obesity, and diabetes. and insulin, that promote visceral adiposity, metabolic abnormalities and cardiovascular complications (35).

It is well known that insulin sensitivity decreases with advancing age and is closely correlated with increased body fat. After years of obesity, persistent resistance to glucose uptake (despite the compensatory mechanism of elevated glycemia and insulinemia) gradually leads to type 2 diabetes mellitus and the pathogenesis of metabolic syndrome.

Despite the evident relationship between obesity and insulin, a relevant study demonstrated that OSAS and insulin resistance were present even in non-obese subjects (36). In recent decades, OSAS has emerged as a heavily researched topic, especially in view of its clinical consequences. Punjabi and co-workers (37) reported insulin resistance even in mild forms of sleep apnea.

To determine whether pathogenic mechanisms of sleep apnea were observed in disorders in which insulin resistance is a primary abnormality, Vgontzas and co-workers (38) investigated if this sleep disorder was present in women with polycystic ovary syndrome. They found that polycystic ovary syndrome women were 30 times more likely to suffer from sleep disordered breathing than controls. The data suggest that, in fact, insulin resistance is probably a primary factor involved in the pathogenesis of OSAS.

\section{Influence of sleep disturbances on the onset of diabetes}

There are bidirectional interactions between sleep and the endocrine system. Several hormones have the capacity to affect sleep but recent research has started to describe sleep as the key factor in physiological restitution, with far-reaching medical implications.

The sleep cycle is closely related to endocrine and metabolic function and to sympathovagal balance, with sleep deprivation being detrimental to these systems (Figure 1). Therefore, although the primary function of sleep may be cerebral restoration, sleep debt also has consequences for peripheral function, that, if maintained chronically, could have an impact on carbohydrate metabolism and endocrine function, including decreased glucose tolerance and insulin sensitivity (8). These effects are similar to those seen in normal ageing and, therefore, it would not be unreasonable to raise the hypothesis that sleep debt increases the severity of age-related chronic disorders (39) such as type 2 diabetes.

Various epidemiological studies have been conducted in order to determine the relationship between sleep and the incidence of diabetes (Table 2). West and colleagues 
(40), investigating a hospital-based population of 1600 men, reported prevalence of OSAS among $31 \%$ of patients with high risk of developing diabetes and $13 \%$ among the low risk patients. Another investigation demonstrated that sleep disturbances may contribute to the development of insulin resistance and type 2 diabetes either directly, by their deleterious effect on glucose regulation components, or indirectly, by deregulating appetite, leading to weight gain and obesity, a major risk factor for insulin resistance and diabetes (41). Studies have demonstrated that sleepdisordered breathing is associated with cardiovascular complications, including alterations in systemic blood pressure $(42,43)$. Multiple mechanisms have been proposed to link sleep-disordered breathing with cardiovascular disease: increased sympathetic activity, endothelial dysfunction, and metabolic dysregulation (44). Therefore, although the primary function of sleep may be restoring brain functions, and in view of the evidence that sleep modulates metabolic and endocrine regulation (45), sleep disturbances may very well have long-term adverse effects on health (39).

\section{Sleep loss}

Chronic sleep loss is increasingly common in industri- alized societies, affecting about $45 \%$ of adults (6). Normal average sleep duration has decreased from 8.0-8.9 h per night in 1960 (46) to about 6.9-7.0 h in 2000-2002. This sleep impairment may result from various common sleep disturbances, such as insomnia and OSAS and may lead to striking alterations in metabolic and endocrine functions (39). Furthermore, long-term sleep loss may represent a novel risk factor for weight gain, insulin resistance, and type 2 diabetes.

A recent prospective study on women has indicated an interesting association between sleep patterns and lateronset type 2 diabetes mellitus. It was observed that a greater incidence among both short-term ( $<6 \mathrm{~h})$ and longterm (>8 h) sleepers (34), as well as sleep loss, have been related to glucose tolerance and to increased risk of type 2 diabetes $(47,48)$.

An important factor that may contribute to the pathogenesis of type 2 diabetes is the higher plasma concentrations of interleukin- 6 (IL-6) and tumor necrosis factor- $\alpha$ (TNF- $\alpha$ ) regardless of obesity or insulin resistance $(4,49)$. These inflammatory cytokines play an important role in mediating peripheral insulin resistance by inhibiting glucose uptake by fat and muscle tissue, increasing the concentrations of counter-regulatory hormones, and inducing the release of free fatty acids via stimulation of

Table 2. Effects of sleep disturbances on the onset of predictor components of diabetes.

\begin{tabular}{|c|c|c|c|c|c|}
\hline Sleep disturbances & Metabolic disorders & Sample & Age (years) & Gender & References \\
\hline Sleep restriction & $\begin{array}{l}\text { Glucose tolerance decreased } 40 \% \\
\text { Insulin response decreased } 30 \%\end{array}$ & 11 normal men & $18-27$ & $\mathrm{M}$ & 39 \\
\hline $\begin{array}{l}\text { Apneics: } \\
\text { decreased total } \\
\text { sleep time, stage } 2 \\
\text { and REM sleep }\end{array}$ & $\begin{array}{l}\text { High body mass index, central obesity, } \\
\text { insulin resistance, glucose tolerance }\end{array}$ & $\begin{array}{l}14 \text { OSAS } \\
11 \text { obese } \\
12 \text { controls }\end{array}$ & $38-49$ & $\mathrm{M}$ & 4 \\
\hline Sleep loss & $\begin{array}{l}\text { Insulin response decreased } 40 \% \text { in } \\
\text { short sleepers }\end{array}$ & $\begin{array}{l}13 \text { short sleepers } \\
14 \text { normal sleepers }\end{array}$ & $23-42$ & $\mathrm{M} / \mathrm{F}$ & 5 \\
\hline OSAS & $\begin{array}{l}10 \% \text { diabetes } \\
6 \% \text { glucose intolerance } \\
40 \% \text { obesity } \\
47 \% \text { overweight }\end{array}$ & 81 apneics & $27-75$ & M & 18 \\
\hline $80 \%$ OSAS & $\begin{array}{l}\text { Apneics: high body mass index, central } \\
\text { obesity, large neck circumference, } \\
\text { glucose intolerance, insulin resistance }\end{array}$ & $\begin{array}{l}197 \text { possible sleep } \\
\text { apneics }\end{array}$ & $42-52$ & M & 36 \\
\hline $\begin{array}{l}4.3 \% \text { short sleepers } \\
4.5 \% \text { long sleepers }\end{array}$ & $\begin{array}{l}\text { Increased risk for diabetes (short and } \\
\text { long sleepers) } \\
11.5 \% \text { snoring (long sleepers) }\end{array}$ & 70,026 & $30-55$ & $\mathrm{~F}$ & 34 \\
\hline
\end{tabular}

$\mathrm{M}=$ male; $\mathrm{F}$ = female; $\mathrm{REM}=$ rapid eye movements; OSAS = obstructive sleep apnea syndrome. 
lipolysis (50). A recent study has demonstrated that a restriction of sleep of $2 \mathrm{~h} /$ night for 1 week in young healthy men and women is associated with a significant increase in sleepiness, decrements in psychomotor performance, and increased secretion of the proinflammatory cytokines IL-6 and TNF- $\alpha$ (51).

Additionally, sleep restriction is associated with reductions in leptin (the appetite suppressant), elevations in ghrelin (the appetite stimulant) and increased appetite, especially for foods with high carbohydrate contents (47). Sleep loss, therefore, seems to alter the ability of leptin and ghrelin to accurately signal caloric needs and could lead to excessive caloric intake when food is freely available (47). Evidence suggests a possible role for chronic sleep loss in the current epidemic of obesity (47).

One study found that short-duration or partial sleep deprivation ( $4 \mathrm{~h}$ of sleep per night for 6 nights), experienced by 11 young men triggered impaired glucose tolerance, higher secretion of evening cortisol concentrations, increased sympathetic nervous system activity, and reduced leptin secretion (39). Another study reported that a one-week period of sleep restriction ( $4 \mathrm{~h}$ of sleep) in young, healthy subjects could produce a prediabetic state (8).

Although long-term sleep loss is often secondary to somatic or psychiatric illness, it appears that insomnia may play a more central role in the pathogenesis of somatic illness and metabolic dysregulation (52). An association between sleep duration and increased risk of developing diabetes has been reported by researchers, who also offered a number of speculative explanations (53). One hypothesis was that excessive sleep per se could directly lead to an increased risk of diabetes. Another is that long sleep duration may be an early symptom of diabetes, possibly predating its official diagnosis (34). There is the need for further research to better elucidate the biological mechanism underlying this association, and to determine whether the etiology of habitually short sleep time affects long-term health (34).

\section{Obstructive sleep apnea syndrome}

Sleep apnea is a chronic condition characterized by a heterogeneous group of disorders including reduction or complete cessation of airflow during sleep, associated with impairment of daytime functions. At least $2-4 \%$ of the general population may be affected and there are much higher estimates based on demographic variables such as age, gender, and body mass index (54). A marked association may be observed between obesity, snoring and sleep apnea, and it has been found that heavy snoring is both a major manifestation and predictor of OSAS (55). Among morbidly obese patients with sleep apnea and type 2 diabetes, nasal continuous positive airway pressure treatment for 4 months improved insulin responsiveness (41).

A human study has shown that individuals acutely exposed to hypoxia, either in a high-altitude setting (56) or in the context of an experimental paradigm (57), present reduced glucose tolerance with a concomitant increase in circulating concentrations of adrenaline. An important point here, however, is that exposure to sustained hypoxia (at high altitudes, for example) is not associated with persistent abnormalities in glucose homeostasis (57).

Obstructive episodes may lead to a number of acute pathophysiological consequences including intermittent hypoxia, severe sleep fragmentation, and activation of the sympathetic nervous system. Each episode of hypoxemia, with larger desaturations, is accompanied by transient periods of sympathoexcitation that can influence glucose homeostasis by increasing glycogen breakdown and gluconeogenesis (58). Furthermore, autonomic activation in sleep apneics may also increase corticotropin-releasing hormone, cortisol production and inflammatory cytokines (IL-6 and TNF- $\alpha$ ) (52). Vgontzas and co-workers (38) have shown that obese persons with sleep apnea have higher IL-6 concentrations than obese persons without sleep apnea. In that study, the investigators also suggested that IL-6 production by adipocytes might contribute to chronic low-level systemic inflammation in obese persons (38). Furthermore, given that TNF- $\alpha$ is thought to modulate somnolence and fatigue, this cytokine may have a role in mediating the constitutional symptoms of OSAS (59).

In summary, the effects of increased sympathetic activity, alterations in glucocorticoid homeostasis, and the effects of intermittent hypoxia may contribute to the development of glucose intolerance and insulin resistance in sleep disordered breathing (60). Furthermore, these episodes of respiratory disturbance may induce frequent arousal episodes and the consequent sleep loss may also facilitate the development of metabolic disturbances (39).

\section{Literature search strategy}

In this systematic review, we identified reports using a Medline search through the PubMed database (19782007) by combining the key words sleep and apnea with diabetes, metabolic syndrome, obesity, and insulin resistance. We searched citation lists in retrieved papers to identify additional references. Papers were selected on the basis of the best available evidence for each specific question discussed. Only English language papers were included. 


\section{References}

1. Wild S, Roglic G, Green A, Sicree R, King H. Global prevalence of diabetes: estimates for the year 2000 and projections for 2030. Diabetes Care 2004; 27: 1047-1053.

2. Birkeland KI, Berg JP. Type 2 diabetes - preventable, but how? Eur J Endocrinol 2001; 145: 573-575.

3. Mooradian AD. Diabetic complications of the central nervous system. Endocr Rev 1988; 9: 346-356.

4. Vgontzas AN, Papanicolaou DA, Bixler EO, Hopper K, Lotsikas A, Lin HM, et al. Sleep apnea and daytime sleepiness and fatigue: relation to visceral obesity, insulin resistance, and hypercytokinemia. J Clin Endocrinol Metab 2000; 85: 1151-1158.

5. Mander BA, Colecchia E, Spiegel K, Van Cauter EY. Short sleep: A risk factor for insulin resistance and obesity. Sleep 2001; 24 (Abstract A74).

6. Bonnet $\mathrm{MH}$, Arand $\mathrm{DL}$. We are chronically sleep deprived. Sleep 1995; 18: 908-911.

7. Spiegel K, Knutson K, Leproult R, Tasali E, Van Cauter E. Sleep loss: a novel risk factor for insulin resistance and type 2 diabetes. J Appl Physiol 2005; 99: 2008-2019.

8. Van Cauter E, Polonsky KS, Scheen AJ. Roles of circadian rhythmicity and sleep in human glucose regulation. Endocr Rev 1997; 18: 716-738.

9. Trenell MI, Marshall NS, Rogers NL. Sleep and metabolic control: waking to a problem? Clin Exp Pharmacol Physiol 2007; 34: 1-9.

10. Resnick HE, Redline S, Shahar E, Gilpin A, Newman A, Walter R, et al. Diabetes and sleep disturbances: findings from the Sleep Heart Health Study. Diabetes Care 2003; 26: 702-709.

11. Alberti KG, Zimmet $P$, Shaw J. The metabolic syndrome - a new worldwide definition. Lancet 2005; 366: 1059-1062.

12. Czupryniak L, Saryusz-Wolska M, Pawlowski M, Wojcik J, Loba J. Distribution of the components of the NCEP ATP IIIdefined metabolic syndrome in newly diagnosed diabetes and non-diabetes Caucasian subjects; implications for metabolic syndrome prevention and treatment. Exp Clin Endocrinol Diabetes 2007; 115: 187-191.

13. Alexander CM, Landsman PB, Teutsch SM, Haffner SM. NCEP-defined metabolic syndrome, diabetes, and prevalence of coronary heart disease among NHANES III participants age 50 years and older. Diabetes 2003; 52: 12101214.

14. Meier U, Gressner AM. Endocrine regulation of energy metabolism: review of pathobiochemical and clinical chemical aspects of leptin, ghrelin, adiponectin, and resistin. Clin Chem 2004; 50: 1511-1525.

15. Kougias $P$, Chai $H$, Lin $P H$, Yao $Q$, Lumsden $A B$, Chen $C$. Effects of adipocyte-derived cytokines on endothelial functions: implication of vascular disease. J Surg Res 2005; 126: 121-129.

16. Sinha MK, Opentanova I, Ohannesian JP, Kolaczynski JW, Heiman ML, Hale J, et al. Evidence of free and bound leptin in human circulation. Studies in lean and obese subjects and during short-term fasting. J Clin Invest 1996; 98: 12771282.

17. Park KG, Park KS, Kim MJ, Kim HS, Suh YS, Ahn JD, et al. Relationship between serum adiponectin and leptin concentrations and body fat distribution. Diabetes Res Clin Pract
2004; 63: 135-142.

18. Schafer H, Pauleit D, Sudhop T, Gouni-Berthold I, Ewig S, Berthold HK. Body fat distribution, serum leptin, and cardiovascular risk factors in men with obstructive sleep apnea. Chest 2002; 122: 829-839.

19. Polotsky VY, Wilson JA, Haines AS, Scharf MT, Soutiere SE, Tankersley CG, et al. The impact of insulin-dependent diabetes on ventilatory control in the mouse. Am J Respir Crit Care Med 2001; 163: 624-632.

20. Vgontzas AN, Kales A. Sleep and its disorders. Annu Rev Med 1999; 50: 387-400.

21. Bixler EO, Vgontzas AN, Lin HM, Ten HT, Rein J, VelaBueno A, et al. Prevalence of sleep-disordered breathing in women: effects of gender. Am J Respir Crit Care Med 2001; 163: 608-613.

22. Guilleminault C, van den Hoed J, Mitler MM. Clinical overview of the sleep apnea syndrome. In: Guilleminault C, Dement WC (Editors), Sleep apnea syndromes. New York: Alan R. Liss, Inc.; 1978. p 1-12.

23. Strohl KP, Redline S. Recognition of obstructive sleep apnea. Am J Respir Crit Care Med 1996; 154: 279-289.

24. Lugaresi E, Cirignotta F, Geraldi R, Montagna P. Snorinig and sleep apnea: natural history of heavy snores disease. In: Guilleminault C, Partinen M (Editors), Obstructive sleep apnea syndrome. New York: Raven Press; 1990. p 25-36.

25. Lavie $P$. Sleep apnea in the presumably healthy working population - revisited. Sleep 2002; 25: 380-387.

26. Vgontzas AN, Legro RS, Bixler EO, Grayev A, Kales A, Chrousos GP. Polycystic ovary syndrome is associated with obstructive sleep apnea and daytime sleepiness: role of insulin resistance. J Clin Endocrinol Metab 2001; 86: 517520.

27. Lopes LA, Lins CM, Adeodato VG, Quental DP, de Bruin $\mathrm{PF}$, Montenegro RM Jr, et al. Restless legs syndrome and quality of sleep in type 2 diabetes. Diabetes Care 2005; 28: 2633-2636.

28. Vgontzas AN, Bixler EO, Tan TL, Kantner D, Martin LF, Kales A. Obesity without sleep apnea is associated with daytime sleepiness. Arch Intern Med 1998; 158: 1333-1337.

29. Zimmet P, Alberti KG, Shaw J. Global and societal implications of the diabetes epidemic. Nature 2001; 414: 782-787.

30. Spiegelman BM, Flier JS. Obesity and the regulation of energy balance. Cell 2001; 104: 531-543.

31. Wurtman RJ, Wurtman JJ. Brain serotonin, carbohydratecraving, obesity and depression. Obes Res 1995; 3 (Suppl 4): 477S-480S.

32. Vgontzas AN, Tan TL, Bixler EO, Martin LF, Shubert D, Kales A. Sleep apnea and sleep disruption in obese patients. Arch Intern Med 1994; 154: 1705-1711.

33. Vgontzas AN, Bixler EO, Chrousos GP. Metabolic disturbances in obesity versus sleep apnoea: the importance of visceral obesity and insulin resistance. J Intern Med 2003; 254: 32-44.

34. Ayas NT, White DP, AI-Delaimy WK, Manson JE, Stampfer MJ, Speizer FE, et al. A prospective study of self-reported sleep duration and incident diabetes in women. Diabetes Care 2003; 26: 380-384.

35. Chrousos GP, Gold PW. A healthy body in a healthy mind and vice versa - the damaging power of "uncontrollable" 
stress. J Clin Endocrinol Metab 1998; 83: 1842-1845.

36. Ip MS, Lam B, Ng MM, Lam WK, Tsang KW, Lam KS. Obstructive sleep apnea is independently associated with insulin resistance. Am J Respir Crit Care Med 2002; 165: 670-676.

37. Punjabi NM, Sorkin JD, Katzel LI, Goldberg AP, Schwartz AR, Smith PL. Sleep-disordered breathing and insulin resistance in middle-aged and overweight men. Am J Respir Crit Care Med 2002; 165: 677-682.

38. Vgontzas AN, Bixler EO, Papanicolaou DA, Chrousos GP. Chronic systemic inflammation in overweight and obese adults. JAMA 2000; 283: 2235.

39. Spiegel K, Leproult R, Van Cauter E. Impact of sleep debt on metabolic and endocrine function. Lancet 1999; 354: 1435-1439.

40. West SD, Nicoll DJ, Stradling JR. Prevalence of obstructive sleep apnoea in men with type 2 diabetes. Thorax 2006; 61 : 945-950.

41. Brooks B, Cistulli PA, Borkman M, Ross G, McGhee S, Grunstein RR, et al. Obstructive sleep apnea in obese noninsulin-dependent diabetic patients: effect of continuous positive airway pressure treatment on insulin responsiveness. J Clin Endocrinol Metab 1994; 79: 1681-1685.

42. Amin RS, Carroll JL, Jeffries JL, Grone C, Bean JA, Chini B, et al. Twenty-four-hour ambulatory blood pressure in children with sleep-disordered breathing. Am J Respir Crit Care Med 2004; 169: 950-956.

43. Marcus CL, Greene MG, Carroll JL. Blood pressure in children with obstructive sleep apnea. Am J Respir Crit Care Med 1998; 157: 1098-1103.

44. Shamsuzzaman AS, Gersh BJ, Somers VK. Obstructive sleep apnea: implications for cardiac and vascular disease. JAMA 2003; 290: 1906-1914.

45. Van Cauter E, Knutson K, Leproult R, Spiegel K. The impact of sleep deprivation on hormones and metabolism. Medscape Neurol Neurosurg 2005; 7: 1-6.

46. Kripke DF, Simons RN, Garfinkel L, Hammond EC. Short and long sleep and sleeping pills. Is increased mortality associated? Arch Gen Psychiatry 1979; 36: 103-116.

47. Sridhar GR, Madhu K. Prevalence of sleep disturbances in diabetes mellitus. Diabetes Res Clin Pract 1994; 23: 183-
186.

48. Scheen AJ, Byrne MM, Plat L, Leproult R, Van Cauter E. Relationships between sleep quality and glucose regulation in normal humans. Am J Physiol 1996; 271: E261-E270.

49. Vgontzas AN, Bixler EO, Chrousos GP. Sleep apnea is a manifestation of the metabolic syndrome. Sleep Med Rev 2005; 9: 211-224.

50. Stumvoll M, Haring $H$. Insulin resistance and insulin sensitizers. Horm Res 2001; 55 (Suppl 2): 3-13.

51. Vgontzas AN, Zoumakis E, Bixler EO, Lin HM, Follett $H$, Kales A, et al. Adverse effects of modest sleep restriction on sleepiness, performance, and inflammatory cytokines. $J$ Clin Endocrinol Metab 2004; 89: 2119-2126.

52. Akerstedt T, Nilsson PM. Sleep as restitution: an introduction. J Intern Med 2003; 254: 6-12.

53. Mallon L, Broman JE, Hetta J. High incidence of diabetes in men with sleep complaints or short sleep duration: a 12year follow-up study of a middle-aged population. Diabetes Care 2005; 28: 2762-2767.

54. Zhang Y, Proenca R, Maffei M, Barone M, Leopold L, Friedman JM. Positional cloning of the mouse obese gene and its human homologue. Nature 1994; 372: 425-432.

55. Kump K, Whalen C, Tishler PV, Browner I, Ferrette V, Strohl $\mathrm{KP}$, et al. Assessment of the validity and utility of a sleepsymptom questionnaire. Am J Respir Crit Care Med 1994; 150: 735-741.

56. Larsen JJ, Hansen JM, Olsen NV, Galbo H, Dela F. The effect of altitude hypoxia on glucose homeostasis in men. $J$ Physiol 1997; 504 (Part 1): 241-249.

57. Oltmanns KM, Gehring H, Rudolf S, Schultes B, Rook S, Schweiger $U$, et al. Hypoxia causes glucose intolerance in humans. Am J Respir Crit Care Med 2004; 169: 1231-1237.

58. Smith ML, Niedermaier ON, Hardy SM, Decker MJ, Strohl $\mathrm{KP}$. Role of hypoxemia in sleep apnea-induced sympathoexcitation. J Auton Nerv Syst 1996; 56: 184-190.

59. Hatipoglu $\cup$, Rubinstein I. Inflammation and obstructive sleep apnea syndrome: how many ways do I look at thee? Chest 2004; 126: 1-2.

60. Punjabi NM, Polotsky VY. Disorders of glucose metabolism in sleep apnea. J Appl Physiol 2005; 99: 1998-2007. 